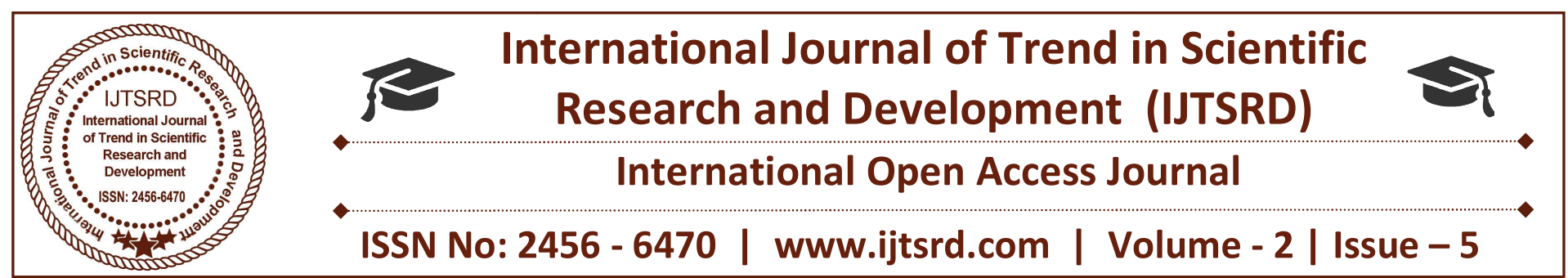

\title{
Design and Implementation of Smart Trolley for Automatic Billing System
}

\author{
Aye Thandar Htwe ${ }^{1}$, Aye Wint Mon ${ }^{2}$ \\ ${ }^{1}$ Assistant Lecturer, ${ }^{2}$ Lecturer \\ Department of Electronic Engineering, Pyay Technological University \\ Republic of the Union of Myanmar, Pyay (Western Bago), Myanmar (Burma)
}

\begin{abstract}
Now-a-day shopping in supermarket and mall is increasing rapidly. While shopping, customers have to face some difficulties. First, they go at the billing counter for payments their total expenditure but there are many people standing in queue for billing purpose. This is unnecessary waste time for customer because cashier scans each item bought with barcode. Barcode technology is time consuming process. Second, customers can't predict their total expenditure so, overall purchase total is greater than their budged. Thus, the proposed system overcomes all of these drawbacks faced by customers in shopping malls. To reduce customer's waste time, the system uses RFID (Radio Frequency Identification) technology. The proposed system will be implemented into two parts. First part is the customer side which initialize arduino for the set ups of RFID reader and zigbee. In this part, contains the tag detection of products by RFID reader which are placed in the trolley and sending of product information from trolley to central billing unit through zigbee transmitter. Second part is counter side which contain zigbee receiver is connected to billing PC using serial communication. It receives billing data and gives it to the PC by using Visual Basic 6.0 software and maintains daily record by Microsoft Access database system.
\end{abstract}

KEYWORD: zigbee, Visual Basic 6.0, Microsoft Access

\section{INTRODUCTION}

RFID (Radio Frequency Identification) are widespread and taking role in many advanced projects

due to its fast and effective response. RFID tags are used for unique identification of products by using radio waves. RFID offer more advantages over conventional barcodes as they have a major drawback which is line of sight technology and also these barcode tags have constraints in its durability whereas the RFID's tags are more durable and able to $\mathrm{read} / \mathrm{write}$ data which could even be encrypted. These tags could hold plenty of data like products name, price and other information using their identification number. By implementation this RFID technology for unique representation of each product in a market and shopping trolley installed with and RFID technology, shopping is done more easily. This could be done by having shopping trolley installed with an RFID reader to scan each product and load it which is control a controller. In proposed system, customers will place their items bought in front of reader and put items into the trolley. RFID reader read product information contained tag. As a person put the products, the costs will get added to the total bill. The record of the items bought is stored in the controller memory along with their individual costs as well as total expenditure. The information such as name and price of items and total expenditure will be display on a LCD screen which will also be placed on the trolley for the customer to verify the item bought and to keep track on the amount spent on each item. Then, customer can reduce their items bought when the overall purchase total is greater than their budget. Thus the billing will be done in the trolley. This system will help save time for customer after shopping they don't have to wait in queue for payment at the billing counter. The recorded data can be sent wirelessly to the main 
database at the counter of the mall by using Zigbee S2C. Mall or shop owner can maintain effectively a daily/weekly record of each product and judge his shop requirement and consumers consumption. Using Zigbee, controller will send this information to central billing computer. Billing computer will print the bill. This system will take less time to calculate bill for large scale applications. The proposed system will help shorten the checkout line.

\section{LITERATURE SURVEY}

Nowadays, if a customer would like to buy something at a shopping mall, customer need to take the particular items from the display shelf and then queue up and wait for their payment. Problem will surely arise when the size of a shopping mall is relatively huge and sometimes customers don't even know where certain items are placed. Besides, customers also need to queue for a long time at the counter for their payment. Because, cashier has to scan every single item and then followed by making payment will definitely take plenty of time.

On the other hand, consumers often have to worry about plenty of things when going to the shopping mall. For example, most customers will worry the amount of money brought is not enough to pay for all the things that wanted to be bought until it comes pay at the cashier.

It will be a great convenience if the information of items that are available in the shopping mall can be obtained. It will be a great improvement on the existing system if the technology of RFID is implemented. Customers will be able to get information of all the items at shopping mall, total up the prices of items as they shop, and save unnecessary time at the cashier.

\section{PROPOSED SYSTEM METHODOLOGY}

\section{A. Operation}

The propose methodology is the automated billing for a customer during shopping primarily based on RFID supported with other simple technologies. In shopping malls or supermarket, the products are provided with RFID tags instead of barcodes. The shopping trolleys include the setup containing RFID reader, LCD display and wireless Zigbee transmitter. On the billing side the system would be making software for getting the itemized bill. This software will be make using Visual Basic 6.0 and programming would be done in C. At the counter, mall or shop owner can maintain effectively a daily/weekly record of each product with Microsoft Access database system. Fig. 1 shows the block diagram of proposed system.

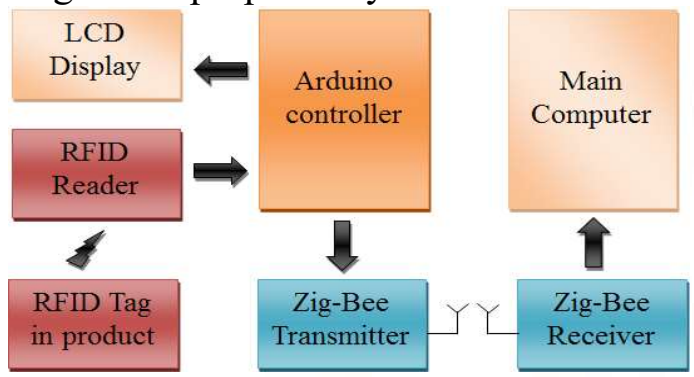

Fig 1: Block Diagram of Automatic Billing System

RFID reader selected for this system is high frequency (HF) RFID model of MFRC 522. RFID reader is a device used to gather information from an RFID tag, which is used to track individual objects. Arduino is an open-source platform used for building electronics projects. Auduino consists of both a physical programmable circuit board (often referred to as a microcontroller) and a piece of software, or IDE (integrated development environment) that runs on computer is used to write and upload computer code to the physical board. LCD which is the part of output device at the trolley side and $\mathrm{I} 2 \mathrm{C}$ driver is supported in LCD to be connected I2C protocol with arduino to reduce pin connection .In this proposed system, one zigbee is connected to arduino uno and other zigbee to the USB port of PC which acts as central billing unit.

\section{B. Proposed System Flow Chat}

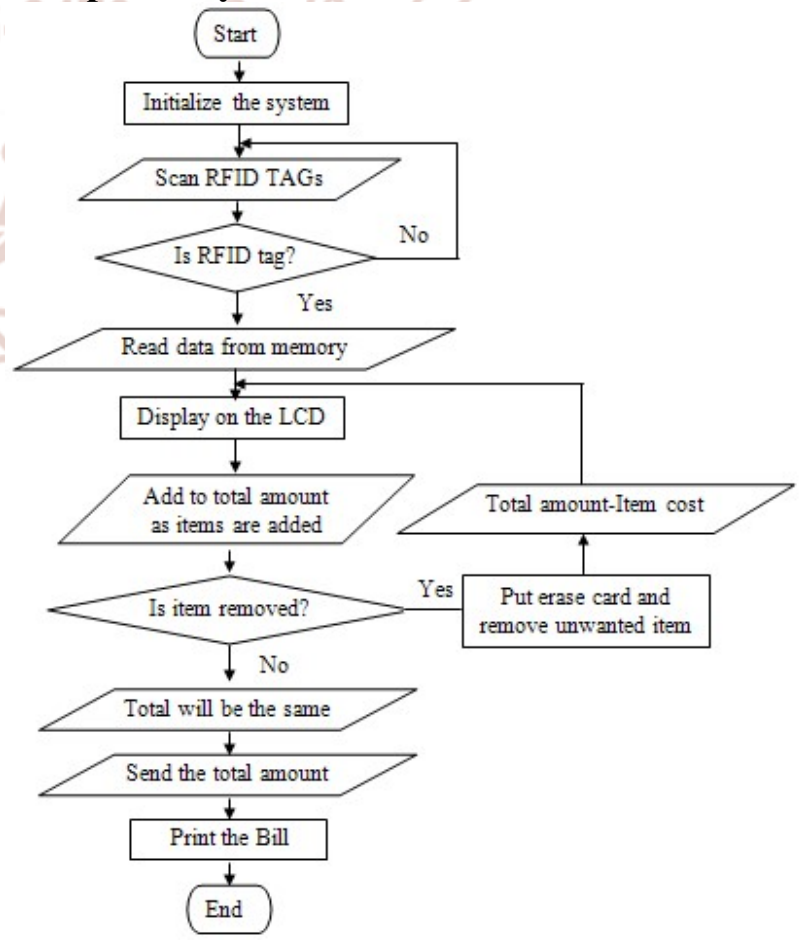

Fig 2: Data Flow Diagram 
In Fig. 2 the flow chat of the proposed system is shown. It states that after initialising the system the reader will scan for RFID tags. If RFID tag is found reader reads the the tag and sends the information to microcontroller which then compares it with data stored in memory. If the tag matches with the data stored it will display data on the LCD. If items keep on adding it goes on adding to the total amount. If item from trolley is removed, put erase card and remove unwanted item then it deducts cost of that specific item from total amount. Then after adding of items is done total amount is send to central billing unit.

\section{EXPERIMENT AND RESULT}

The proposal finally resulted in an effective outcome where RFID technology replaced barcode due to its drawback where barcode requires the line of sight and should be placed in its exact boundary while scanning, but RFID's only constraint to be considered is its distance coverage. RFID tags are more durable than the barcode which damaged due to temperature, water, physical tear etc. This ensures the process of scanning easy and precise. Fig. 3 show the hardware connection of system and the bill display on LCD. The digital input pins 9, 10,11, 12, 13 of arduino uno are connected to RST, SDA, MOSI, MOSO, SCK of RFID reader which operates $3.3 \mathrm{~V}$ VCC. LCD which operates $5 \mathrm{~V}$ with $\mathrm{I} 2 \mathrm{C}$ backpack contains SDA and SCL which are connected to $\mathrm{A}_{4}$ and $\mathrm{A}_{5}$ of arduino respectively. Zigbee is used for send product's information between customer and counter computer. TX-out and RX-in of Zigbee S2C are connected to the microcontroller pin 2, 3 for serial communication. For communication, one of the radios $\mathrm{S} 2 \mathrm{C}$ is configured as coordinator and other one as router. Zigbee operates $3.3 \mathrm{~V}$.

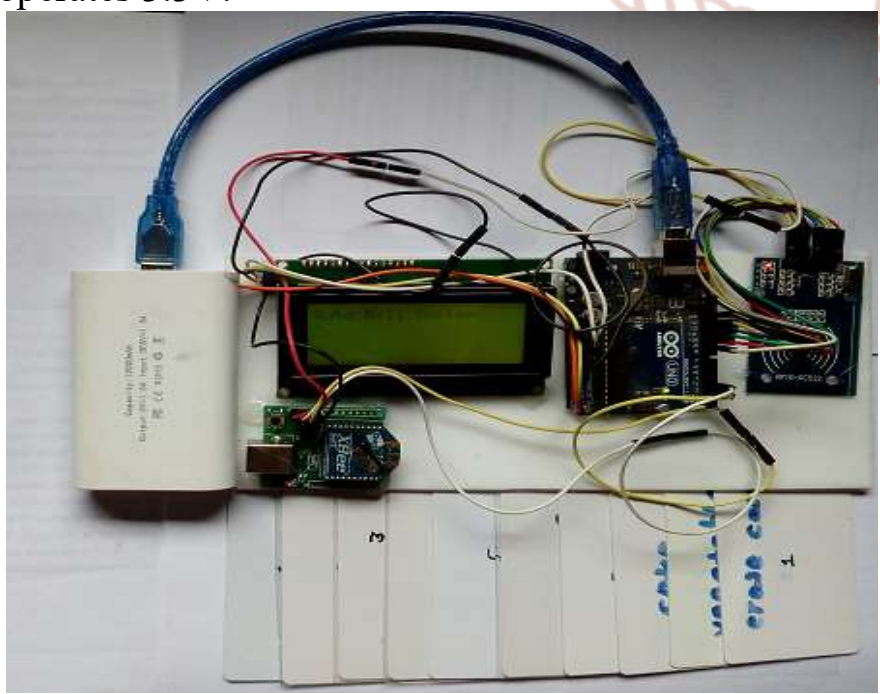

Fig 3: Hardware Architecture
Fig. 4 shows the total bill of purchased product at trolley side. The customer bought first item, ORANGE its price is 300 and the number of different item is one. The overall total expenditure is 300 . The customer bought second item, APPLE its price is 500 and the number of different item is two. The total overall expenditure is 800 . And so on, the customer bought next item they wanted. The customer's bill will be done in trolley.

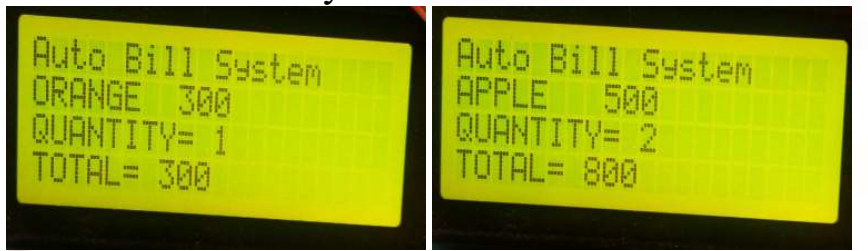

Fig 4: Result From Customer Side

Fig. 5 shows the total bill of purchased product at counter/side. The customer bought first item, the corresponding product's information of this item will be arrived at cashier counter and show with Visual Basic 6.0 software. The corresponding product's information of the next items of the customer bought will be arrived sequentially.

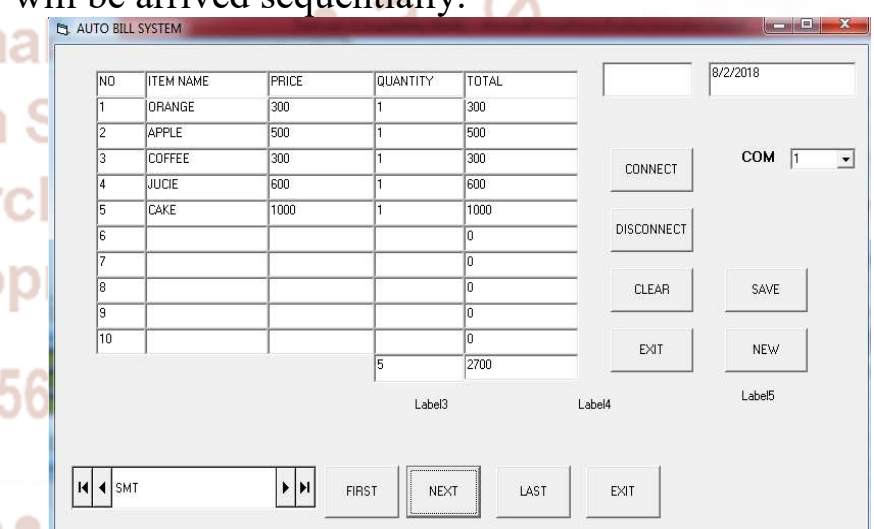

Fig 5: Tatal Bill at Counter Side

Fig.6 shows the result for shop owner to see his shop requirement. The shop owner can see consumers consumption on each product by recording Microsoft Access database software.

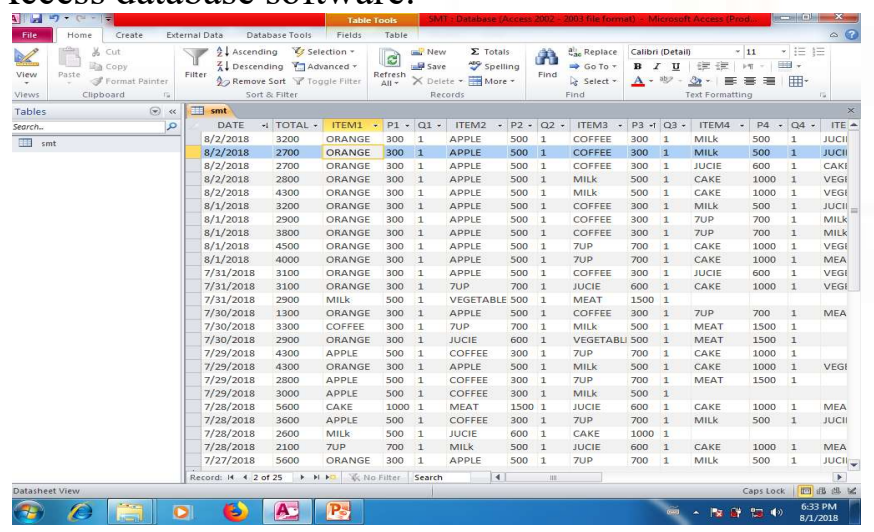

Fig 6: Database Access for Shop Owner 


\section{CONCLUSION}

The proposed system for use in supermarkets will be advantage for shopping as it would make shopping easier. Now, the customer needs not to stand in a queue to pay the bill. The system makes billing automatic. The idea of this paper was drawn from large queues at the shopping mall and the inconvenience that it causes to the customer. This new system of billing is fast as the single product detail gets recorded as it dropped into the trolley. Working on this product it was noted that RFID technology and Zigbee is a very vast applications in the near future. Also, RFID is better and faster than barcode reading because the later works on line of sight which is not the case for RFID technology is compact and reliable. Zigbee is the wireless network that connects the costumer to the retailer and is very secure with long range of operation. This intelligent shopping system can completely change the way of shopping. The RFID and Zigbee technology that are most commonly used would definitely find some use commercially. Moreover, this smart trolley will be very beneficial as it would reduce the number of salesmen and billing counters and also prove to be time saver for both customer and the shopper.

\section{REFERENCES}

1. International Journal of Advanced Research Trends in Engineering and Technology (IJRTET). www.ijarter.com
2. Swati Zope, Prof, Maruti Limkar, "RFID based Bill Generation and payment through Mobile", International Journal of Computer Science and network (IJCSN), Volume 1, Issue 3, June 2012.

3. Global Journal of Advanced Engineering Technologies ISSN (Online): 2277-6370 \& ISSN (Print):2394-0921.

4. G. Roussos and B. College, "Enabling RFID", Computer IEEE, Vol39, no.3, 2006, ppt25-30.

5. Mohit Kumar, Jaspreet Singh, Anju, Varun Sanduja (2015) "Smart trolley with instant billing to ease Queues at shopping malls using Aum 7 IPC 2148: a review" International Journal of Advanced Research in Computer and Communication Engineering (Vol.4, Issue \& August2015).

6. www.schneiderelectric.com.hk/resources/access/te $\mathrm{xt} / \mathrm{rfidreader}$

7. http://archieved.computerhistory.org/resources/acc ess Oral History Panel retrieved 2011 June28 page4.

8. RFID JOURNAL, 2002-2007, REFFERD 6.8.2007, http://www.net/vb6/vbtutor.html visual basic 6 tutorial. 